\title{
An Analysis of the Flipped Classroom Based on the Bloom's Taxonomy of the Educational Objectives
}

\author{
Yiting $\operatorname{Lin}^{1 *}$ \\ ${ }^{1}$ Department of Foreign Languages, Concord University College Fujian Normal University, Fuzhou, Fujian, China \\ ${ }^{*}$ Corresponding author. Email: 124022018043@student.fjnu.edu
}

\begin{abstract}
This study utilizes the flipped classroom approach in conjunction with Bloom's taxonomy. Through a series of literature reviews, the author evaluates the merits and downsides of the flipped classroom. This article proposes a method that combines Bloom's taxonomy of instructional goals and flipped classrooms to address instruction problems. This article starts with flipped classroom's history and application. It continues Bloom's taxonomy research and investigates the combination of the flipped classroom and Bloom's taxonomy. The findings show that the flipped classroom has several drawbacks. To begin, its inconsistency arises from the variety of course categories; Secondly, instructors cannot get immediate feedback when producing the pre-class study material. Thus, measures to these shortcomings should begin with curriculum design and effective instructor-student interaction. According to the results, educators must improve their ability to engage students and alter their design of classroom activities. Teachers must do various additional tasks, including guiding, encouraging, and diverting traditional teaching methods toward more constructive learning programs.
\end{abstract}

Keywords: The Flipped Classroom, The Bloom's Taxonomy of Educational Objectives.

\section{INTRODUCTION}

In 1992, King decided that teachers should guide the side instead of the sage on the stage. Carrying on the spirit, Khan Academy was established in 2006, an online classroom with a library of over 3200 videos and 350 practice exercises. The online classroom is a novel method to spread knowledge, becoming a source of the instructor's pre-class micro-video. Teachers of the flipped classroom take advantage of the online classroom to offer a helpful tool to students.

Flipped classrooms have become popular as a new type of pedagogical method. It emerged as an innovative solution to improve student-centered learning that integrates pre-class video teaching and in-class discussion [1]. Instructors find such model time-effective in preparing course materials in advance. Clyde and Nancy listed the advantage of the flipped classroom: 1) educators may modify and update the curriculum and offer it to students at any time of day; 2) students move ahead at their speed; 3) the results of the flipped classroom include an improvement in students' performance, interest, and participation, according to educators who are implementing this method [2].
Yet, flipped classroom mode has many deficiencies. Firstly, when preparing materials before class, teachers cannot receive timely feedback. Teachers may be unaware of students' doubts about the difficult knowledge points. Secondly, an examination of the course content is inconsistent in terms of subjects, student level and expected outcomes [3-5]. When students are not mature enough to develop independent and constructive ideas, it is not easy to organize a meaningful discussion in class. Besides, students probably lack self-disciplined and have poor selflearning consciousness, as online learning is not constrained by time and space.

For all the above mentioned issues, many researchers realized that Bloom's taxonomy could be the breakthrough point that improves flipped classrooms [6] $[7,8]$. Bloom's taxonomy of educational objectives is a hierarchical model that helps course designers to classify educational learning objectives into levels of complexity and specificity. It includes instructional design, curriculum development and instructional evaluation [3]. The core theoretical analysis of Bloom's taxonomy needs to be linked to the flipped classroom. The classification of educational goals in the cognitive field is an important part of Bloom's taxonomy of educational objectives, which aims to provide criteria for evaluating students' 
learning results and guide teaching. The classification divides educational goals into six levels: remember, understand, apply, analyze, evaluate, creation. The "remember" and "understand" categories were collapsed into one category called "knowledge" and any item in this category was considered a "low" level cognition item [8]. David and Jorie researched to determine if the flipped classroom relative to the lecture classroom increases student performance. Performance on FOM final examination anatomy items categorized by Bloom's taxonomy served as the main study outcome [8]. Average performance for anatomy final examination items assessing Bloom's level of cognition was computed for each student. This research found that the flipped classroom and the lecture classroom have no difference in students' ability to the materials of knowledge level on a final examination. In contrast, the flipped classroom method improved students' ability to analyze material on a final examination relative to the lecture classroom. Thus, this research demonstrates that the flipped classroom method is most beneficial in facilitating students' ability to analyze material in undergraduate medical education.

In this paper, the author aims to improve the performance of flipped classrooms based on Bloom's taxonomy of educational objectives. This paper starts with analyzing existing flipped classroom research and practice experience.

\section{THE FLIPPED CLASSROOM}

\subsection{History of the flipped classroom}

Some educational ideologies from the early 20th century stressed how important it is to engage students in finding answers and solutions to real-life issues [9]. An innovative option for improving student-centered learning is the flipped classroom concept. The development of this concept can be traced back to earlier educational concepts of pragmatism, progressivism and reconstructionism by John Dewey [10]. Accordingly, learning was more about finding and producing information rather than only acquiring it. Not only is it up to teachers to generate and disseminate knowledge, but imperative to shift the conventional style of teachers as the center to a student-centric style. Supporters believe that learners are responsible for the synthesis [9][10]. This educational philosophy contributes to the efficiency of flipped classrooms [10].

As the internet has grown, online classrooms have played a major part in popularizing flipped classrooms. A pioneering program is Khan Academy, which has produced over 3200 videos and 350 practice activities since 2006. Khan Academy's declared mission is to provide "free, world-class education to anybody wherever in 2012" [11]. In addition to Khan Academy, Mooc, Coursera, TED, and other large open online course providers, new resources have been created and extended to support the flipped classroom technique, enhancing its credibility even further [10].

\subsection{Definition}

The flipped classroom model is a method of teaching and learning in which students watch a video lesson outside of class via distance learning and then participate in hands-on activities in class. The flipped classroom has emerged as one of the most innovative educational methods in recent years. It is improved with the progress of electronic technology.

Students are increasingly adopting media technologies. Yet, it is difficult for instructors to attract students' attention in a regular classroom [12]. Besides, students have become less tolerant of passive learning settings, such as lectures, while they are more active participants in the learning [12]. In other words, the field of education changes as students' needs change. So, the "flipped classroom," also known as the "inverted classroom," is gaining favor among teachers. "Learning environments that include technology as an authentically integral part of learning activities foster emergent and adaptive practices" [12].

Unlike typical classes, flipped classrooms require students to learn course information before class instead of assigning assignments after lectures [11]. Next, students work on practice projects, receive individualized tutoring or participate in higher-order thinking exercises [13].

Teachers no longer spoon-fed the knowledge to students but expect them to acquire topics and perform tasks independently at a speed that suits them. In this way, students can avoid being left behind by class discussions that move too quickly or becoming bored by class time spent reviewing material they already know [11]. The flipped classroom places students at the center of learning and gives them control over their education. Students are far more likely to retain and use the knowledge when they actively process it by reassembling it in new and personally meaningful ways. As a result of this learning method, one may develop vast cognitive structures that connect new concepts to what is already known by reformulating given information or creating new knowledge depending on what is presented [14]. The flipped classroom is an excellent teaching mode for students' knowledge construction since it enables students to engage in divergent thinking while still assisting students in deepening their comprehension and application of knowledge. 


\subsection{Elements of the effective flipped classroom}

An effective flipped classroom contains learning tools, professional instructors, designed course structure and procedure.

Learning tools are created to help teachers identify students' questions based on the amount of time students spend browsing and the duration of their browsing. Before class, teachers use statistical data to construct a case analysis to help students overcome doubts. In addition, the designed course structure and procedure organize the class discussions that centralize students. Instructors inquire about issues that the students encounter with self-study beforehand. In this way, teachers can sum up their teaching experience and make continuous improvements, which will enhance the instructor's professional teaching skills. Research shows that a successful flipped classroom has the following characteristics: (1) students become more active learners, rather than passive listeners; (2) homework is done before class, with class time being set up to help students with personalized instruction; (3) content is connected to real-world scenarios; (4) students spend either class time working on especially challenging concepts or higherorder critical thinking and problem solving [10].

\subsection{Research in the flipped classroom}

However, the flipped classroom method has certain drawbacks.

Teachers cannot comprehend all students' uncertainties about knowledge points and hence cannot resolve all students' concerns in terms of curriculum development. Without adequate information before class, some students cannot comb the class content in advance, which is unhelpful to group discussion in class.

Despite the volatility and unpredictability of the flipped classroom's effect on student learning, educators worldwide are paying attention and considering it. A flipped classroom approach may lead to inconsistencies because it is utilized in a variety of classes. As tested in flipped classrooms, higher and lower levels of learning have contributed to these outcomes. In contrast, this may result from the contrast in the levels of learning, higher and lower order, that are evaluated when assessing student learning in a flipped classroom [5]. The flipped classroom is not appropriate for every subject and age group. This method is challenging to utilize in primary school since students often lack the skills to conduct autonomous discussions and critical analysis.

Student motivation is another area of the issue about the flipped classroom. Flipped classrooms, while providing self-paced learning, are seen to be less suited to pupils who have a lack of drive [10]. In general, less driven students have an easier time of it when courses are more traditional. Student-centered learning centers around empowering students to manage their education, enabling them to take on a role of responsibility and autonomy. Student motivation and self-driven work outside of class is essential to the success of the flipped classroom. Various research projects demonstrated that adopting the flipped classroom environment positively impacted student motivation and thus learning. For example, Davies said that students could learn from simulation and were encouraged to learn independently; they also noticed that students wanted to recommend the flipped classroom to other friends [15].

An author interviewed teachers about flipped classrooms. Teacher A is a social studies teacher who utilizes YouTube videos to interact with his students. This approach is wonderful for teaching fundamental ideas, but it "puts too much on a freshman," implying that they are not "mature enough" to be responsible for their own learning. He says it could be beneficial for seniors. He believes that burdening freshmen pupils with so much topic knowledge would backfire [12].

Instructor B, a science teacher, started utilizing flipping in 2010. As Kelly explains, Teacher B's method is to have students learn outside of class and then discuss it in class. Teacher B records her lessons to save time in class. She claims it is a new approach to accountability. "I did not think students wanted. Student volunteers decide this." She struggles to persuade kids to pay attention in class. A quiz from the previous night's class stops her work. It takes time to set up, she explains. In this section of the discussion, Teacher B describes how long it takes to prepare for flipping. Her students' participation in lectures might have been reduced, while their students' engagement has grown. So, she evaluates AP scores' influence on student learning and achievement. It also helps her be more consistent in her teaching approaches, she claims. As the author mentioned before, the flipped classroom approach may lead to inconsistencies because it is utilized in various classes, while Teacher B's new pedagogy can help to decrease the inconsistent in the flipped classroom. "I will know who has been paying attention to my lectures since every student will have access to the same information." Students are more engaged." Teacher B reports mixed feedback. She feels her teaching method has made the course material more challenging and increased student responsibility for learning and future preparation. Her lectures' topics allow her to use more pictures, which she feels helps students retain information. Many individuals are afraid of these and similar educational approaches, she admits. "We need to focus on teachers' technology comfort." Teaching a flipped classroom is not for everyone, says Teacher B [12]. Teacher B uses the flipped classroom to enhance her unique teaching method to improve student engagement and performance. Teacher B uses visual aids to help students remember. Jyrki's multimedia learning proposal supports this technique. The employment of different forms, such as 
words and images, allows for multimedia learning. Researchers have discovered that multimedia presentations with scientific explanations lead to meaningful learning [16]. Ultimately, the flipped classroom has its benefits and disadvantages depending on the instructor's teaching style and educational priorities. This paper will explore methods to employ Bloom's taxonomy of educational objectives to solve flipped classroom shortcomings and promote flipped classroom effectiveness.

\section{BLOOM'S TAXONOMY OF THE EDUCATIONAL OBJECTIVES}

\subsection{Development trend}

Abigail Adams said that in 1780, learning was not gained by accident. It must be sought for with vigor and pursued with vigor." All of the following skills learning, teaching, goal setting, and critical thinking are tied together in a tangled web. Bloom took great pains to explain these ideas and untangle this complicated matter, making the process painstaking and extremely persistent. The goal of his life's work became boosting student learning [17].

In 1948, the American Psychological Association (APA) held a conference where Bloom promoted a group of educators who would ultimately take on the massive project of organizing educational goals and objectives. They hoped to create a categorization system for learning behaviors that they thought to be crucial. Ultimately, this concept formed a taxonomy of three domains: The cognitive, the affective, and psychomotor. The cognitive domain is a knowledge-based realm made up of six layers [17]. This article will focus on Bloom's taxonomy of the educational objectives in the cognitive domain.

Despite Bloom's endorsement of the word "taxonomy," some inside the group did not support its usage due to a lack of familiarity with the concept in the education community. Bloom ended up winning, making his name synonymous with the term forever. The examiners' edition of the little book has been changed into a universal resource for educators across the globe. To everyone's surprise, the term has been utilized by curriculum designers, administrators, researchers, and instructors in classrooms of all grades" [17].

\subsection{Definition}

Taxonomy of Educational Objectives was introduced in 1956 by Benjamin Bloom with collaborators Max Englehart, Edward First, Walter Hill, and David Krathwohl. Teachers at the K-12 and college levels have used this framework for decades, often known as Bloom's Taxonomy. Bloom's Taxonomy has been translated into twenty-two languages since its first publication and is among the most broadly used and most often cited references in education [17]. The conceptual framework developed by Bloom and his collaborators was divided into six categories: remember, understand, apply, analyze, evaluate, creation. The categories "remember" and "understand" were condensed into one category termed "knowledge," and all items in this category were deemed "low" level cognitive items. The categories of "skills and abilities" which followed knowledge were identified as such because the idea was that knowledge was a necessary prerequisite for these skills and abilities to be used. The taxonomy is widely known for its six major divisions, but each category also has subcategories ranging along a continuous spectrum from simple to complex and tangible to abstract [17]. Bloom's taxonomy of educational objectives is a hierarchical system that aids course designers in organizing their education.

\subsection{Implement}

Bloom's Taxonomy has endured the test of time and remains an important tool for educators. Due to its extensive and well-known history and many abbreviations, alterations, and revisions, it has been changed significantly. Research results reveal various applications and interpretations, from close overviews to difficulties and specifics to the widening of application learning goals.

Firstly, as a tool to assist students in learning, Bloom's Taxonomy is used in many classrooms. Some researchers readily acknowledged that the grading rubrics were difficult to define with any degree of accuracy. How a B student's effort fell short on specific criteria is tough to convey to ambitious students. Initially, the class uses model papers projected and evaluated. The B student did not find it beneficial that the A's paper is more engaging, has a more defined stance, and shows rigorous, critical thought and understanding of the strategic principles. "Tell me what to do," student B asked. "I will study till I pass." We all required a common vocabulary and set of actions to help the learner identify the next stages and continue self-directed and selfmanaged learning [18]. It is pretty complex to define the gap between the perfect and good.

As in the above case example, Bloom's taxonomy can be used as the basis for a feedback mechanism. The taxonomy created by Bloom is a good foundation for a feedback mechanism, as shown in the example above. Thus, the taxonomy helps tackle a problem every faculty member faces how to help students understand the criteria used to assess their work in a way that makes sense to them. Managers need to understand that writing case studies and presentations are two parts of the management strategy; other courses include journals, research papers, field projects, and/or exams. Everyone has their own criterion of the work's quality. How to solve this phenomenon? The taxonomy functions as a 
common language to communicate cognitive sophistication, a key component of competency-based education. Athanasiou and McNett's conversations centered on both the curriculum and students' comprehension of it. Current education scholars term scaffolding with Bloom's taxonomy as a metacognitive framework [18]. Bloom's taxonomy act as a common language to identify the criterion of the grade.

Secondly, as a self-assessment tool for students to judge their grasp of the subject matter and as a feedback mechanism for students to evaluate their own work in various tasks, including case write-ups, diary entries, and other activities, we found our taxonomy to be quite useful. They are usually mixed. While the taxonomy aids students in understanding cognitive activities, an advanced capstone course in strategic management, for example, requires students to employ taxonomy knowledge. To analyze the case, students use their marketing, corporate finance, management, and accounting knowledge. In comprehension, students use their memory of functional information to make sense of the case material they are reading. Beginners have more challenges at this level. They recall ideas but not details. They sketch out the scenario but stop there [18].

Thirdly, Crompton and Burke have researched patterns to identify the levels of cognition that students are involved in when engaged in mobile learning tasks. The last decade has seen an outpouring in mobile learning in schools. This has led to claims about the ability of mobile learning to improve and expand student cognitive engagement. The research is on what Bloom's Taxonomy levels kids are working at when working on PK-12 mobile learning projects. Research shows that just $8.9 \%$ of the time do students engage in memory tasks while on a mobile device [7]. An example of Bloom's Taxonomy level one activities involved students needing information about 25 creatures that inhabit five continents. Students were provided with a game that allowed them to ponder on the topic matter [19]. Understanding, level two, engaged students $32.7 \%$ of the time. In a level two lesson, students used tablets to see a 3D solar system simulation and alter the representations to understand planetary orbits better [7]. At level three, Students used knowledge $15.8 \%$ of the time. At level four, $7.9 \%$ of students were engaged by the Analysis module. An example of level four involved students using mobile devices to play a forensics science game. To crack the case, they had to use the tools of investigative science to investigate evidence [7]. The results reveal that each level of Bloom's taxonomy has its unique relevance. Based on the preceding study, Bloom's taxonomy is a successful analysis method.

\subsection{The incorporation of the flipped classroom and Bloom's taxonomy of the educational objectives}

The incorporation of Bloom's taxonomy into the flipped classroom is an advantageous combination. One example of this would be to consider the college English reading and writing class. The flipped classroom provides a range of benefits and challenges to teachers. After the flipped classroom approach, traditional teaching methods like memorizing definitions, grammar rules, and vocabulary are outdated. Teachers must learn to engage students more and design classroom activities, assignments, and projects. Previously, teachers were only there to educate students; today, they are expected to do much more, including guiding, helping, promoting, and assessing students and shifting conventional teaching into a more constructive learning service. In addition, the usage of taxonomy will make the flipped classroom and taxonomy combo more effective and help accomplish desired outcomes. The teacher reinforces Bloom's classification of objectives by repeating it to the students. In addition to having the target classification in mind when solving different learning problems, students will often consider the level of the goal classification to which the present issue belongs. This makes it apparent that the instructor's frequent mentions of Bloom's theories had an encouraging and important impact on students throughout the whole semester.

Another example is a good introductory article about impressing others, in Section A of Unit 4 of Reading and Writing Course 1. The language is comprehensible and well-structured. Students will fail to get excited and participate in class when the teacher overlooks any creative part and continues to keep to the text content. It is thus possible to start class with comprehension and application exercises. For instance, the text's teaching goals are based on Bloom's taxonomy's levels of memory, which will be set like "Learn and remember the pronunciation, spelling and meaning of "impression", "be conscious of", "range", "encounter", "be committed to", "at one's best". The educator's evaluation level had a few creative questions, such as "How do you believe the text's suggestions on making a good impression apply to you?" "What would you do to make a good impression if you were going to a job interview?" "Review the plays and select the best one according to the teacher's instructions." [20]. The flipped classroom and Bloom's taxonomy of the educational objectives are well combined in this case. Therefore, it will effectively improve the previous classroom model and helps to enhance students' participation in class and interest in learning.

To the weakness of the flipped classroom, there are some suggestions to promote it. 
First of all, instructors cannot get instant feedback while creating the pre-class micro-video. They cannot be aware of the students' uncertainty regarding complex knowledge topics. This problem can be solved by implementing Bloom's taxonomy, which provides an approach to improving the efficiency of learning. Their comprehension level shows college students' ability to comprehend and understand the material covered in the English reading and writing class. Teachers need to know their students' attitudes toward their subject matter based on performance in class and assessments before class. Learners who provide comments beforehand are given supplementary resources and micro-class films. Afterward, monitor the efficiency of group discussion in class, and take a quiz at the end of class to enhance student comprehension via these strategies. From the examples given above, it can be inferred that Bloom's taxonomy of the educational objectives can aid instructors in systematically understanding the objective hierarchy. Additionally, it helps students process knowledge and solves problems more systematically and comprehensively. It enables students to consciously categorize the essence of problems and think through their answers more purposefully, which is more helpful in answering questions accurately and avoids the chance of being sidetracked.

Secondly, the inconsistent of the flipped classroom. Inconsistent of the flipped classroom means the impact that the flipped classroom gave to the students. For instance, some students may already be acquainted with the flipped classroom model and therefore better suited to learn using a combination of pre-class knowledge and open discussion in class, which is more effective for them. Others, however, may not be able to adjust to the new classroom approach, have been unable to learn independently and need teachers to explain their knowledge. Because of this, it is not clear to these students how the benefits of the flipped classroom would enhance their learning and may even harm their learning. Ibrahim concluded that the inconsistent of the flipped classroom is comprised of these two points: 1) These inconsistencies may have resulted from the differences in the types of courses that the flipped classroom pedagogy is applied in; 2) They may have also resulted from the different levels of learning, higher vs. lower order, that are assessed when measuring student learning in a flipped classroom [5]. Instead of only having one flipped classroom style in the school, this deficiency could be resolved by implementing many flipped teaching methods. For instance, the teacher can gather students' questions about various writing types when teaching English composition. Teachers can provide templates and writing strategies for a variety of writing assignments. Potential solutions must be examined in light of the different curricula that are utilized in the flipped classroom. The author wishes that this research can help inspire future studies. In addition, the use of Bloom's taxonomy of educational objectives allows teachers to classify learning difficulties. Only by giving students at various levels the opportunity to learn knowledge in a flipped classroom can the advantages of the teaching method be truly realized.

\section{CONCLUSION}

Overall, this paper establishes the combination of the flipped classroom and Bloom's taxonomy. With the literature review of the flipped classroom, it is imperative that the method needs to be developed brand-new solutions to match the different types of curricula. Although there are important discoveries revealed by these studies mentioned before, there are also limitations. First, the inconsistent of the flipped classroom resulted from the differences in the types of courses. Second, instructors cannot get instant feedback while creating the pre-class micro-video. Thus, the solutions to these weaknesses need to be started with curriculum design and effective interaction between instructors and students.

This article aims to identify methods to address the limitations of flipped classrooms via examining previous research on flipped classrooms. The author attempts to integrate Bloom's taxonomy with the flipped classroom and discovers that Bloom's taxonomy effectively increases flipped classroom's efficiency.

\section{REFERENCES}

[1] Bishop, J., \& Verleger, M. A. (2013, June). The flipped classroom: A survey of the research. In 2013 ASEE Annual Conference \& Exposition (pp. 231200).

[2] Herreid, C. F., \& Schiller, N. A. (2013). Case studies and the flipped classroom. Journal of College Science Teaching, 42(5), 62-66.

[3] Hussey, H. D., Richmond, A. S., \& Fleck, B. (2015). A primer for creating a flipped psychology course. Psychology Learning \& Teaching, 14(2), 169-185.

[4] Chen, F., Lui, A. M., \& Martinelli, S. M. (2017). A systematic review of the effectiveness of flipped classrooms in medical education. Medical education, 51(6), 585-597.

[5] Agbenin, I. (2018). The Impact of Flipping an Educational Psychology Classroom on Learning at Different Levels of Bloom's Taxonomy. Perspectives In Learning, 17(1), 4.

[6] Ormell, C. P. (1974). Bloom's taxonomy and the objectives of education. Educational Research, 17(1), 3-18.

[7] Crompton, H., Burke, D., \& Lin, Y. C. (2019). Mobile learning and student cognition: A systematic review of PK-12 research using Bloom's 
Taxonomy. British Journal of Educational Technology, 50(2), 684-701.

[8] Morton, D. A., \& Colbert-Getz, J. M. (2017). Measuring the impact of the flipped anatomy classroom: The importance of categorizing an assessment by Bloom's taxonomy. Anatomical sciences education, 10(2), 170-175.

[9] Eisner, E. W., \& Freeman, S. (2013). NOTES ON COMPOSING AND COMPOSITION. Curriculum \& Teaching Dialogue, 15.

[10] Bates, J. E., Almekdash, H., \& Gilchrest-Dunnam, M. J. (2017). The flipped classroom: A brief, brief history. In The flipped college classroom (pp. 3-10). Springer, Cham.

[11] Davies, R. S., Dean, D. L., \& Ball, N. (2013). Flipping the classroom and instructional technology integration in a college-level information systems spreadsheet course. Educational Technology Research and Development, 61(4), 563-580.

[12] Snowden, K. E. (2012). Teacher perceptions of the flipped classroom: Using video lectures online to replace traditional in-class lectures. University of North Texas.

[13] Khan, S. (2012). The one world schoolhouse: Education reimagined. Twelve.

[14] King, A. (1993). From sage on the stage to guide on the side. College teaching, 41(1), 30-35.

[15] Zainuddin, Z., \& Halili, S. H. (2016). Flipped classroom research and trends from different fields of study. International review of research in open and distributed learning, 17(3), 313-340.

[16] Mayer, R. E., Suomala, J., \& Shaughnessy, M. F. (2000). An interview with Richard E. Mayer: about technology. Educational Psychology Review, 477483.

[17] Forehand, M. (2010). Bloom's taxonomy. Emerging perspectives on learning, teaching, and technology, 41(4), 47-56.

[18] Athanassiou, N., McNett, J. M., \& Harvey, C. (2003). Critical thinking in the management classroom: Bloom's taxonomy as a learning tool. Journal of Management Education, 27(5), 533-555.

[19] Sandberg, J., Maris, M., \& De Geus, K. (2011). Mobile English learning: An evidence-based study with fifth graders. Computers \& Education, 57(1), 1334-1347.

[20] Liu, X. (2015). Exploration of flipped Classroom in College English Reading and writing Based on
Bloom's Target Classification. College English (Academic Edition) (01), 16-20, 26. 